\title{
ĐỀ XUẤT SỬ DỤNG KINH TUYẾN TRỤC THỐNG NHẤT CHO BẢN ĐỒ ĐỊA CHÍNH CÁC TỈNH KHI QUY ĐỊNH Độ CHÍNH XÁC CỦA BẢN ĐỒ TÍNH TỬ GIÁ TRỊ ĐẤT
}

\author{
ThS. NGUYẼ̃N PHI SO'N \\ Viện Khoa học Đo đạc và Bản đồ
}

\section{Tóm tắt:}

Sai số diện tích của thửa đất từ mặt vật lý Trái đất về mặt phẳng UTM bao gồm sai số do biến dạng diện tích do ảnh hưởng của phép chiếu (trong phép chiếu UTM: chiếu từ mặt ellipsoid WGS84 về mặt phẳng - hình trụ khai triển thành mặt phẳng) và sai số do đo đạc vị trí điểm góc thửa đất gây nên. Trong bài báo này đã tính toán và so sánh biến dạng diện tích của thửa đất khi đo theo độ chính xác được đề xuất mới từ giá trị đất tính trên kinh tuyến trục thống nhất cho các tỉnh với sai số biến dạng diện tích do múi chiếu gây ra. Kết quả của việc so sánh này đã đi đến kết luận rằng "sai số do biến dạng diện tích do múi chiếu là rất nhỏ so với sai số diện tích thửa đất do đo đạc gây ra", từ đó đề xuất cần thiết nên quy định kinh tuyến trục múi $3^{\circ}$ thống nhất cho các địa phương thay cho quy định kinh tuyến trục theo từng tỉnh.

\section{1. Đặt vấn đề}

$\mathrm{V}$ iệc quy định kinh tuyến trục cho từng tỉnh trong đo vẽ thành lập bản đồ địa chính ở nước ta đã được đặt ra từ Quy phạm địa chính năm 1999. Việc sử dụng kinh tuyến trục riêng cho từng tỉnh trong đo vẽ thành lập bản đồ địa mặc dù giảm được phần nào sai số biến dạng diện tích do ảnh hưởng của múi chiếu nhưng đã gây những bất cập trong việc tích hợp dữ liệu địa chính ở phạm vi vùng, phạm vi khu vực và các yêu cầu ở phạm vi quốc gia và nhất là một hệ thống địa chính hiện đại cần phải quản lý các loại bản đồ chuyên ngành đất đai như bản đồ hiện trạng sử dụng đất, bản đồ quy hoạch sử dụng đất và các bản đồ chuyên đề khác... đều phải tích hợp với hệ thống bản đồ địa hình quốc gia.

Từ kết quả của nghiên cứu [Nguyễn $P h i$ Sơn (2012)] khi đề xuất quy định độ chính xác vị trí điểm trên ranh giới thửa đất theo cách tiếp cận từ giá trị đất, đã đặt ra vấn đề "có cần quy định kinh tuyến trục theo từng tỉnh hay không”. Để chứng minh được điều này, cần phải tiến hành so sánh giữa sai số diện tích thửa đất do sai số đo đạc theo độ chính xác mới đề xuất trên múi $3^{0}$, kinh tuyến trục thống nhất $\left(102^{\circ}, 105^{\circ}, 108^{\circ}\right)$ với sai số biến dạng diện tích do múi chiếu gây ra.

\section{Giải quyết vấn đề}

\subsection{Sai số diện tích do đo đạc}

Trong tài liệu [Hà Minh Hòa (2008)] đã thiết lập quan hệ giữa sai số trung phương tương đối của diện tích thửa đất với sai số trung phương tương đối ước tính giá đất:

$$
\frac{m_{P}}{P} \leq \frac{1}{4} \frac{m_{C_{0}}}{C_{0}}
$$

Quan hệ này xác lập cơ sở khoa học, để từ sai số trung phương tương đối của ước tính giá đất $\left(\frac{m_{C_{0}}}{C_{0}}\right)$ có thể xác định sai số trung 


\section{Nghiên cứu}

phương tương đối của diện tích thửa đất do đo đạc $\left(\frac{m_{P_{a d}}}{P}\right)$. Từ đây xác định được yêu cầu độ cnınn xác của điểm trên ranh giới thửa đất cần đo đạc $m_{x y}$. Căn cứ theo quan hệ (1) mà trong [Nguyễn Phi Sơn (2012)] đã tiến hành điều tra thực tế trên địa bàn 3 tỉnh thành đại diện cho các vùng đồng bằng, trung du và miền núi là Hải Phòng, Hà Nội và Phú Thọ, với 16 xã, phường, thị trấn (1000 phiếu điều tra) đã xác định được
$\left(\frac{m_{C_{0}}}{C_{0}}\right)$ của các loại đất theo bảng sau:

(Xem bảng 1)

Từ bảng 1 , dựa vào công thức (1) xác định được sai số trinn phương tương đối xác định diện tích $\left(\frac{m_{P_{d A}}}{P}\right)$ do đo đạc cho các loại đất như sau: (xem oảng 2)

2.2. Sai số diện tích do biến dạng múi chiếu

Khi xem xét sai số tương đối biến dạng diện tích do lưới chiếu đã được [Nguyễn Trọng San (2009)] đưa ra là:

Bảng 1: Kết quả điều tra sai số trung phương ước tính giá đất theo loại đất

\begin{tabular}{|c|l|c|}
\hline STT & \multicolumn{1}{|c|}{ Loại đất } & $\left(\frac{m_{C_{0}}}{C_{0}}\right)$ \\
\hline 1 & Đối với đất phi nông nghiệp tại đô thị & 0,0331 \\
\hline 2 & Đối với đất ở và đất chuyên dùng khu vực nông thôn & 0,0411 \\
\hline 3 & Đối với khu vực đất sản xuất nông nghiệp trồng cây hàng năm & 0,0600 \\
\hline 4 & Đối với khu vực đất sản xuất nông nghiệp trồng cây lâu năm & 0,0731 \\
\hline 5 & Đối với khu vực đất lâm nghiệp & 0,0702 \\
\hline
\end{tabular}

Bảng 2: Sai số trung phương tương đối của diện tích do đo đạc

\begin{tabular}{|c|l|c|}
\hline STT & \multicolumn{1}{|c|}{ Loại đất } & $\left(\frac{m_{P_{d f}}}{P}\right) \% \leq$ \\
\hline 1 & Đối với đất phi nông nghiệp tại đô thị & 0,008275 \\
\hline 2 & Đối với đất ở và đất chuyên dùng khu vực nông thôn & 0,010275 \\
\hline 3 & Đối với khu vực đất sản xuất nông nghiệp trồng cây hàng năm & 0,015000 \\
\hline 4 & Đối với khu vực đất sản xuất nông nghiệp trồng cây lâu năm & 0,018275 \\
\hline 5 & Đối với khu vực đất lâm nghiệp & 0,017550 \\
\hline
\end{tabular}




$$
P=P_{u t m}-P_{u t m}\left(\frac{y}{R}\right)^{2} \text { hay } \frac{P}{P_{U T M}}=1-\left(\frac{y}{R}\right)^{2}
$$

Ở đây diện tích thửa $P$ trên mặt đất và $P_{\text {utm }}$ từ ellipsoid về mặt phẳng bản đồ UTM, $y$ là khoảng cách từ kinh tuyến trục của múi $3^{0}$ đến thửa đất, $R$ là bán kính cong trung bình trái đất $(R \approx 6371 \mathrm{~km})$.

Như vậy bản đồ địa chính ở nước ta nếu được thành lập theo múi chiếu $3^{\circ}$ chính quy $\left(102^{\circ}, 105^{\circ}, 108^{\circ}\right)$ cho 63 tỉnh thành trên cả nước, biến dạng lớn nhất ở kinh tuyến biên của múi chiếu (vị trí cách kinh tuyến trục khoảng $y=160 \mathrm{~km}$ ) có tỷ lệ biến dạng diện tích là:

$$
\left(\frac{m_{P_{b d}}}{P}\right)=\left(\frac{y}{R}\right)^{2} \leq 0,0006307 \%
$$

Ở đây $\left(m_{P_{b d}} / P\right)$ là sai số trung phương tương đối biến dạng diện tích do phép chiếu và múi chiếu gây nên.

2.3. So sánh giữa sai số diện tích do đo đạc và sai số diện tích do biến dạng múi chiếu

Trên thực tế ta có quan hệ: sai số trung phương tương đối xác định diện tích thửa đất bằng tổng sai số trung phương tương đối diện tích thửa đất do đo đạc và sai số trung phương tương đối biến dạng diện tích do phép chiếu và múi chiếu gây nên:

$$
\left(\frac{m_{P_{c x}}}{P_{c x}}\right)^{2}=\left(\frac{m_{P_{d d}}}{P}\right)^{2}+\left(\frac{m_{P_{b d}}}{P}\right)^{2}
$$

Để $m_{P_{c x}}=m_{P_{d d}}$ thì sai số trung phương biến dạng diện tích:

$$
\left(\frac{m_{P_{b d}}}{P}\right) \leq \frac{1}{4}\left(\frac{m_{P_{d d}}}{P}\right)
$$

$\left(m_{P_{c x}} / P_{c x}\right)$ là sai số trung phương tương đối xác định diện tích chính xác;

$\left(m_{P_{d d}} / P\right)$ là sai số trung phương tương đối diện tích do đo đạc.

Từ bảng 2, khi so sánh với sai số tương đối biến dạng diện tích do múi chiếu đã được tính như (3), chúng ta thấy rằng sai số trung phương tương đối diện tích thửa đất do đo đạc cho các loại đất lớn hơn rất nhiều so với sai số trung phương tương đối diện tích do biến dạng múi chiếu. Theo quan hệ như (4) là có thể bỏ qua sai số do biến dạng múi chiếu, do sai số này chỉ đạt 0,0006307\% nhỏ hơn rất nhiều so với sai số

trung phương tương đối của diện tích do đo đạc là $0,008275 \% \div 0,017550 \%$. Điều này có nghĩa là sự biến dạng diện tích do lưới chiếu ở Việt Nam không ảnh hưởng đến sai số trung phương tương đối diện tích các loại đất do sai số đo đạc. Do đó chúng ta thấy rằng việc quy định kinh tuyến trục riêng cho các tỉnh không những không cần thiết mà còn làm phức tạp cho công tác quản lý dữ liệu địa chính thống nhất ở cấp quốc gia.

\section{Kết luận}

Việc nghiên cứu để hoàn chỉnh các văn bản quy phạm trong công tác đo đạc địa chính, phù hợp với sự phát triển của hệ thống địa chính hiện đại là cần thiết. Với đề xuất áp dụng quy định mới về độ chính xác vị trí mặt bằng điểm góc thửa đất khi tính tới giá trị đất đã đặt ra vấn đề thay đổi quy định về kinh tuyến trục địa phương cho toàn bộ dữ liệu địa chính nước ta. Trong bài báo này đã tính toán mức độ sai số về diện tích do phép chiếu và múi chiếu gây nên là nhỏ hơn rất nhiều so với sai số về diện tích do sai số đo đạc mang lại, vì vậy cần xem xét quy định sử dụng kinh tuyến trục thống nhất khi thành lập bản đồ địa chính cho các tỉnh ở múi chiếu $3^{\circ}\left(102^{\circ} ; 105^{\circ} ; 108^{\circ}\right)$ của nước ta. $\mathrm{O}$

(Xem tiếp trang 58) 